\title{
MODELLING THE ASSESSMENT OF INFLUENCE OF INSTITUTIONAL FACTORS ON THE LEARNING PROCESS OF FUTURE BUSINESS MANAGERS
}

\author{
Svitlana Kryshtanovych ${ }^{1}$, Ivan Bezena ${ }^{2}$, Nataliia Hoi ${ }^{3}$, Oksana Kaminska $^{4}$, Neonila Partyko ${ }^{5}$ \\ ${ }^{1}$ Department of Economics and Management, State University of Physical Culture named after Ivan Bobersky, \\ Gorodotksa str. 29, Lviv, Ukraine. Phone No.: +380673611133, E-mail address: skrischtanovich@gmail.com
}

${ }^{2}$ Department of Social and Humanitarian Education, Candidate of Philosophical Sciences. Communal institution of higher education "Dnipro Academy of Continuing Education" of Dnipropetrovsk Regional Council ", Yavorska str. 10, Dnipro, Ukraine. Phone No.: +380965959364, E-mail address: oli2727@yahoo.com

${ }^{3}$ Department of Management and Business Administration, Vasyl Stefanyk Precarpathian National University, Roderov str. 8, Ivano-Frankivsk, Ukraine. Phone No.: +380930469569, E-mail address: tetikoty@yahoo.com

${ }^{4}$ Department of Foreign Languages, Lviv Polytechnic National University, Bandera str. 29, Lviv, Ukraine. Phone No.: +380677022165, E-mail address: t.akobe58@yahoo.com

${ }^{5}$ Department of Theoretical and Practical Psychology, Lviv Polytechnic National University, Bandera str. 29, Lviv, Ukraine. Phone No.: 380675261864, E-mail address: yarologan@yahoo.com

Received 1503 2021; Accepted 13042021

\begin{abstract}
The main purpose is to analyses the experience and the modelling of hierarchy of institutional factors that have their impact on the learning process and the formation of professional competence of business managers. The methodological basis is graph theory and hierarchical structuring methods. A graph is a set of points (vertices) and lines (edges), they are connected. We can also say that a graph is a set of points and lines at which the end of each belongs to a set of points. The data obtained make it possible to systematize the practical and theoretical achievements in the process of learning business managers and using the theory of graphs and the hierarchical ordering modelling, the priority of institutional factors influencing the learning process of business managers were established. The proposed modelling of the level of influence of institutional factors on the learning process of business managers is specific for the study area, since it used expert opinions of persons who are involved in the learning process of business managers. In the future, this simulation can be used for other sectors of higher education. This modelling of the impact of institutional factors can be used for higher education institutions that specialize in learning business managers.
\end{abstract}

Keywords: learning system, graph theory, factor of influence, modelling, business and entrepreneurship managers. JEL Classifications: A13, O11, O13, Q01, Q50.

\section{Introduction}

Today the quality of the educational process is a key problem in the development of human potential in the world, and therefore the education system is aimed at training a competitive business and entrepreneurship managers. Many researchers note that the goals set for higher education can be achieved only through a creative approach to the organization of the educational process. The active and widespread use of educational technologies in higher professional education of business and entrepreneurship managers is a means of increasing the pedagogical skills of teachers and the effective activity of students

Copyright (C) 2021 Author(s), published by Vytautas Magnus University. This is an open access article distributed under the terms of the Creative Commons Attribution Non-Commercial 4.0 (CC BY-NC 4.0) license, which permits unrestricted use, distribution, and reproduction in any medium provided the original author and source are credited. The material cannot be used for commercial purposes. 
in achieving higher educational results, expanding the ability to choose effective ways to solve the problems of professional education in accordance with state standards. It can be argued that the key to high-quality professional training of a specialist- business and entrepreneurship managers is the optimal organization of the educational process in higher education, which provides for a tendency to move from cognition to selfknowledge, self-improvement and a creative approach to activities. Considering the above features of the development and implementation of the training process of future managers are presented, today the analysis of the experience and factors of influence on the training process of future managers has become especially relevant. This study is especially relevant in the context of the fact that on today's day the business and entrepreneurship sphere needs more than ever experienced personnel who understand not only the principles of doing business, but also the basic principles of the economy.

\section{Literature review}

Today, the process of training future managers of business and entrepreneurship is an extremely urgent topic, since this area is today one of the most popular and requires special skills in the field of business and economics from representatives of their field.

For example, Allen (2015) in his work investigated the features of the interconnections of the training process for future business managers and their next performance in the financial and economic field. In addition, his work focuses on basic principles that could improve the general process of adapting business and entrepreneurship managers to work processes.

Chevaillier (2002) and Duque, Weeks (2010) in their worki studied the institutional and internal principles that have the greatest impact on the learning process of students of higher educational institutions. His work was formed on the example of future managers and student economists.
In turn, Bandara, Chand, Chircu, Hintringer, Karagiannis, Recker, Van Rensburg, Usoff, Welke, (2010) and Wilson (2013).in their works investigated the features of the implementation of higher education for economic and financial profile in Western Europe and the USA.

Evans, Pucik, Barsoux (2002) in their work studied the global trends and challenges that arise in the process of personnel management. Their work is not only in highlighting the basic challenges and trends, they tried to combine and compare these phenomena with the peculiarities of training managers in business and economics. In their opinion, the most optimal solution in the process of eliminating these calls is to optimize the learning process and study all the factors that affect it

Grugulis, Styanova, (2020) in their works explored the basic skills that a future business and entrepreneurial manager should possess. According to their views, today there is a basic list of skills that a future business and entrepreneurship manager should master in a higher educational institution. These skills are important not only in the context of professional, but also personal development.

One of the newest studies in this area can be considered scientific work of Petrenko (2020), who investigated the process of training future managers of the competence of intercultural professional interaction in a higher educational institution

Considering the literature presented above, today there are many scientific works that highlight the features of the training process for future business and entrepreneurship managers, as well as the factors that have the greatest impact on it. But it is worth noting that all this data is more unstructured and unsystematic. Given this, today the participants of the educational process, both teachers and students are not able to assess the level of factors that influence the learning process of future managers of business and entrepreneurship. 


\section{Research background}

For the effective implementation of technologies that solve the "learn to do" tasks, it is important to consider the goals for which technology is chosen, the degree of the teacher's methodological culture, it is applied, and the individual psychological characteristics of the subjects of the educational process of business and entrepreneurship managers. The professional training of modern competitive business and entrepreneurship managers must take into account the changes in industrial society associated with the emergence of a new economic system - the knowledge economy. One of the leading places in this system is higher professional education. The evolution of the new economy leads to changes in the system of interaction "state-business-society" in value systems and human needs. Of particular interest, in our opinion, is the transformation processes in education, since this is the sector of the new economy where the carrier of knowledge is formed - a skilled worker.

Education of business and
entrepreneurship managers is now
characterized by an increase in the volume of knowledge and the speed of its updating, the emergence of new skills that determine the success of a person in society. Continuous improvement in response to the challenges of the times becomes a condition for the viability of the education system. Especially relevant is the ability to transform in accordance with the changing requirements of the environment in management education. So, the new economy makes its demands on the existing education system of business and entrepreneurship managers.

As noted by Drucker (2000): "Business development claims that the demand for good managers is growing faster than the opportunities for training them". This is a very modern situation, testifying to the inability of the participants in the market of management education - universities and business schools to provide the business need for relevant business and entrepreneurship managers. This is especially true for the training of specialists who must solve problems at the junction of information technology with management, economics, finance, personnel who are ready to work in the sectors of the new economy. Considering the above, the task of training personnel of a new formation in the field of management is becoming particularly relevant.

One of the countries experienced in conducting the training process for future business and entrepreneurship managers is the United States of America. The paradigm of conducting this process was borrowed by many developed countries of the world, since over the years this system has established itself as stable and effective.

First of all, in our opinion, the following special features of US higher education should be distinguished, which distinguishes it from the educational systems of other countries. In this regard, we focus on the power and flexibility of universities. In the United States, powerful, world-famous higher education institutions operate (Harmon, Wolf, 2014).

The US management training system includes several key components. The training of managers is carried out within the framework of the general education system, in the private network of the American Management Association (AMA) and directly in industrial firms. Professional business schools have elements of university education. But, unlike classical universities, the emphasis in training in them is not on obtaining knowledge itself, but on the formation of professional skills.

The basic higher education in the USA (as well as many other economically developed countries) is considered a bachelor's degree. As an example, consider the curriculum for the preparation of bachelors in the field of "business" and "economy". According to such plans, almost all businessmen, managers and other business professionals undergo basic training. 
Note that the disciplines included in the training program for business and entrepreneurship managers are divided into compulsory and optional disciplines. Compulsory disciplines are taught for scientific and theoretical training of a specialist; they are studied during the first two years. In the last two years of study, special subjects are studied - disciplines of choice (elective). Elective courses (disciplines) are divided into main (limited choice) and optional (free choice). Students choose elective courses (subjects) in accordance with their scientific or practical interest.

Particularly noteworthy is the specifics of undergraduate training at the Concordia University of Wisconsin Business School, a non-governmental institution owned by the Lutheran Church of the Northern States of America with a degree in business, management and economics. The curriculum consists of a compulsory ("core") general education, compulsory (basic) special part, as well as a profiling, that is, a professionally oriented part in the chosen specialty. The bachelor's curriculum for most higher education institutions in the United States contains from 124 to $132-134$ credits depending on the profession and the amount of theoretical and practical training needed, such as universities, its form of ownership, prestige and rating (Bergener, Brocke, Hofmann, Stein, Brocke, 2012).

Describing the peculiarities of preparing Bachelor of Economics and bachelor's in business administration in US universities, Alter (2013) draws attention to a combination of four approaches: pedagogical, informative, methodological, and definitional. The pedagogical approach consists in the obligatory direct participation of students in the teaching process itself, the so-called active learning, not only destroys the barrier between the teacher and students, but also helps and encourages students to form their own attitude to the problem, considered using previously acquired knowledge.
The essence of the informative aspect of teaching economics is the use of models that not only reproduce exclusively the economic aspects of modern life, but also depict their connection with political and social events, is an integral part of the problem. This makes it possible to prepare students for a comprehensive study of an important economic problem. The methodological approach used by American educators consists in introducing students to the realities of the economic world and teaching them methods of analysis and interpretation of economic phenomena. Within the framework of this approach, the feasibility of combining the teaching of economics with the coverage of social, political and cultural factors is also noted, which broadens the horizons of students and their political and social competence. The definitional approach to teaching economics is primarily associated with the definition (definition) of the economy itself. If, according to the classical definition, economics is the science of the distribution of limited resources in accordance with unlimited needs, then in modern American higher education, economics is defined as the science of the interaction of people to provide themselves and the whole society with goods and services. This approach makes it possible to consider economic mechanisms from the social aspects of life.

As we can see, when teaching businessrelated bachelors in US universities, there is a close connection between training and the realities of life, a focus on the formation of a specialist of a certain (sometimes narrow) profile, mastering the experience of a future profession during training, the use of active teaching methods and the latest information technologies.

Given this, it is worth noting that despite the fact that the education system of future managers of business and entrepreneurship has constant positions in training, it also makes it possible to introduce innovations into their mechanisms that are designed to improve its functioning. 


\section{Methods}

Having studied the experience of the developed, in the context of introducing the latest learning methods for business and entrepreneurship managers, the next step will be to assess the level of influence of institutional factors that influence their aforementioned educational process.

To highlight the main institutional factors affecting the learning process for business and entrepreneurship managers, we selected 40 experts from the studied higher education institution. Among these experts were representatives of the teaching, managerial and student staff. Given the existing anti-epidemic measures, communication with experts was limited to online correspondence and a survey. After a thorough survey, we identified seven main institutional factors that have the greatest impact on the learning process of business and entrepreneurship managers:

- implementation of quarantine activities;

- level of economic security;

- financial policy;

-international development and innovation;

- education development system in world;

- regulatory support;

- level of business education in Europe.

But simply identifying and listing the above factors will not be sufficient, since we still do not know the degree of influence of each of the factors on the education process of business and entrepreneurship managers. To do this, we use the hierarchical structuring methodology and graph theory (Sylkin, Kryshtanovych, Zachepa, Bilous, Krasko, 2019).

Graph theory is one of the most extensive sections of discrete mathematics, widely used in solving economic and managerial problems, in programming, chemistry, designing and studying electrical circuits, communication, psychology, psychology, sociology, linguistics, and other fields of knowledge. Graph theory systematically and sequentially studies the properties of graphs, which can be said to consist of sets of points and sets of lines representing the relationships between these points (Hogben, 2004).

\section{Empirical Results and Model Formation}

Descrip In the context of graph theory, suppose that the set of institutional factors that affect the learning process of future managers of physical culture and sports are the set $Z=$ $\left\{Z_{1}, Z_{2} \ldots, Z_{n}\right\}$. From this set we choose a subset $Z_{1} \in Z_{2}$.

For better clarity, the mathematical value of each institutional influence factor is indicated by us with an identical mnemonic name:

$\mathrm{Z}_{1}$ - implementation of quarantine activities (QA);

$\mathrm{Z}_{2}$ - level of economic security (lES);

$\mathrm{Z}_{3}$ - financial policy $(\mathrm{FP})$;

$\mathrm{Z}_{4}$ - international development and innovation (ID);

$\mathrm{Z}_{5}$ - education development system in world (WDS);

$\mathrm{Z}_{6}$ - regulatory support $(\mathrm{RS})$;

$\mathrm{Z}_{7}$ - level of business education in world (LBW).

At the first stage, a subset of the influence factors $\mathrm{Z} 1$ and possible relationships between them, we will present in the form of an orient graph (Figure 1), at the vertices of which the elements of the subset $\mathrm{Z} 1$ are placed, arrows connect adjacent pairs of vertices (zi, zj) for which the relationship is defined. It indicates a certain dependence of one factor (the beginning of the arrow) on another (end of the arrow).

Based on the graph we have constructed; the next step will be constructing the binary dependence matrix $A$ for the set of vertices $Z_{1}$ as follows. 


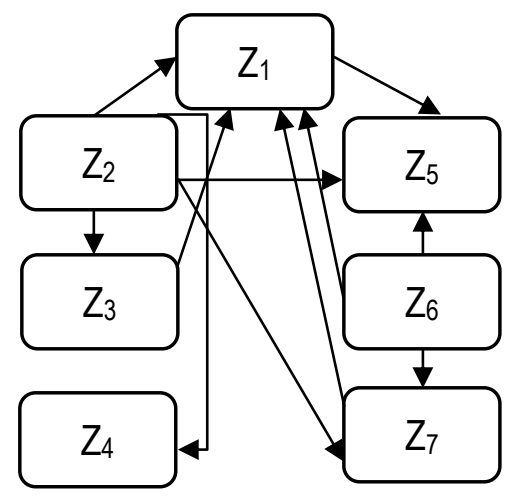

Figure 1. A graph of relationships between institutional factors of influence on the learning process of business and entrepreneurship managers

We place the matrix A with dimensions of $7 \times 7$ elements in the table, adding to it an information line and a column with the names of institutional factors (Table 1).

Table 1. Binary dependence matrix

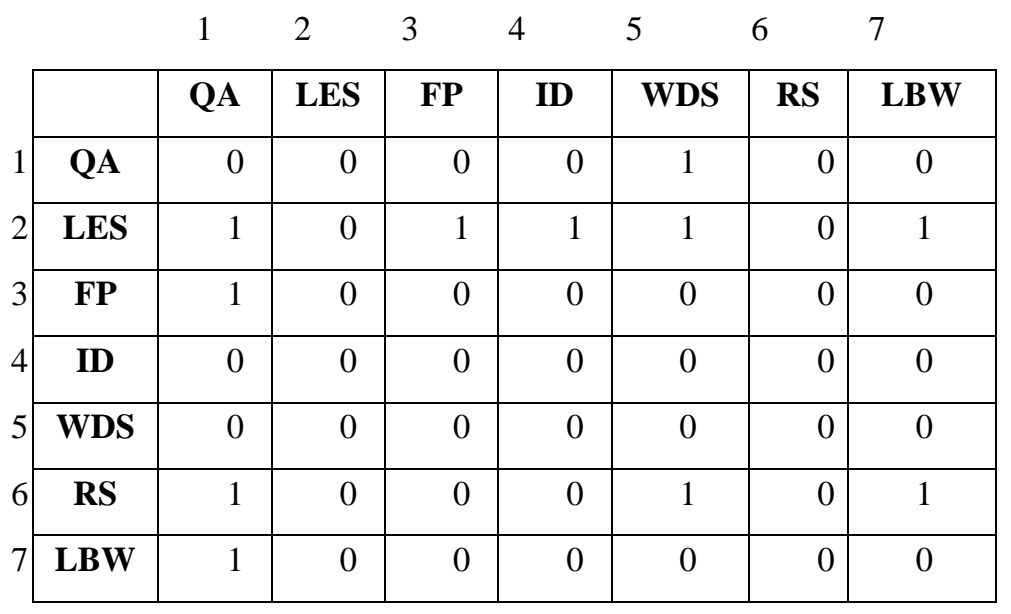

Based on the information presented in matrix A, we construct the reachability matrix. We form the binary matrix $(I+A)$, where $\mathrm{I}$ is the identity matrix. As a result, the reachability matrix must satisfy condition (1):

$$
(\mathrm{I}+\mathrm{A})^{\mathrm{k}-1} \leq(\mathrm{I}+\mathrm{A})^{\mathrm{k}}=(\mathrm{I}+\mathrm{A})^{\mathrm{k}+1}
$$

The formation of a binary matrix is reduced to filling in a table (Table 2), similar to the one above (Table 1), the binary elements of which are determined by rule (2):

$$
b_{i j}=\left\{\begin{array}{c}
1, \text { if from } i \text { it is possible to get to } j \\
0, \text { otherwise }
\end{array}\right.
$$




\section{Sciendo}

Management Theory and Studies for Rural Business and Infrastructure Development

eISSN 2345-0355. 2021. Vol. 43. No. 3: 263-372

Article DOI: https://doi.org/10.15544/mts.2021.33

Table 2. Binary dependence matrix

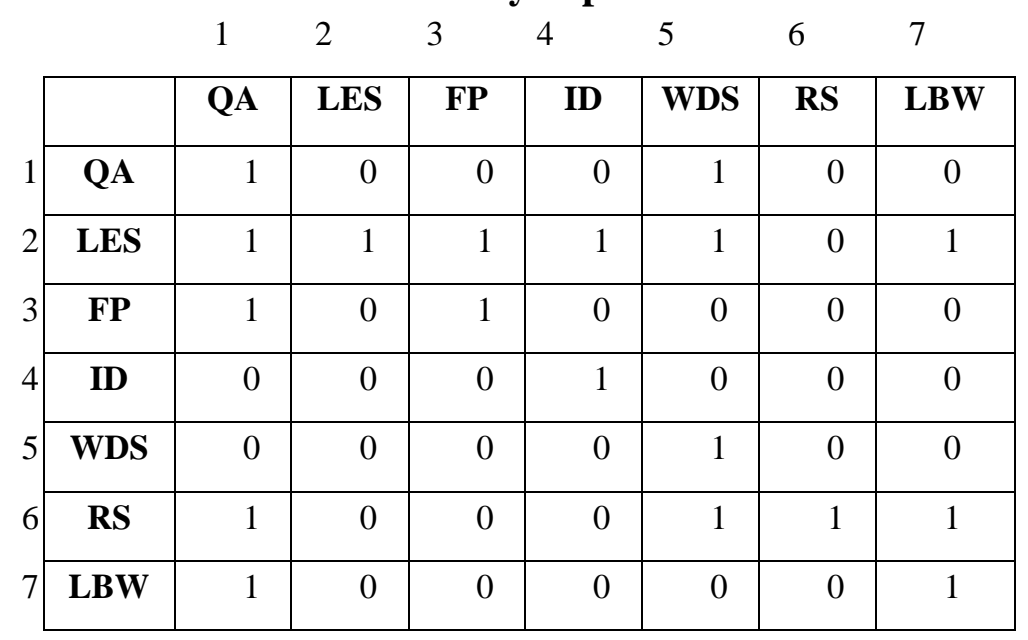

The vertex $z_{j}$ is reached from the vertex $z_{i}$ if there is a path in the graph that leads from the vertex $z_{i}$ to the vertex $z_{j}$. Such a peak is considered achievable. Denote the subset of similar vertices by $\mathrm{S}\left(z_{i}\right)$. Similarly, the vertex $\mathrm{zi}$ is the predecessor of the vertex $z_{j}$ if it reaches its vertex. Assume that the set of predecessor vertices forms a subset $\mathrm{P}\left(z_{i}\right)$.

Finally, the section of the subsets of reachable and predecessor vertices, i.e., the subset (3)

$$
\mathrm{R}\left(\mathrm{z}_{\mathrm{j}}\right)=\mathrm{S}\left(\mathrm{z}_{\mathrm{j}}\right) \cap \mathrm{P}\left(\mathrm{z}_{\mathrm{j}}\right)
$$

The vertices that are not reached from any of the vertices of the set $\mathrm{Z} 1$, the remaining ones, determine a certain level of the hierarchy of priority of the influence of factors assigned to these vertices. An additional condition for this is to ensure equality (4):

$$
P\left(z_{j}\right)=R\left(z_{j}\right)
$$

Performing the totality of the above actions gives the first level (the lowest in terms of the importance of influencing the learning process of business and entrepreneurship managers) of the hierarchy of influence factors. To determine this, based on the preliminary matrix, we build table 3 .

Table 3. Computational table for building a model of the hierarchy of institutional factors affecting the learning process of business and entrepreneurship managers

\begin{tabular}{|c|c|c|c|}
\hline $\mathrm{I}$ & $\mathbf{S}\left(\mathbf{z}_{\mathbf{i}}\right)$ & $\mathbf{P}\left(\mathbf{z}_{\mathbf{i}}\right)$ & $\boldsymbol{S}\left(\mathbf{z}_{\boldsymbol{j}}\right) \cap \boldsymbol{P}\left(\mathbf{z}_{\boldsymbol{j}}\right)$ \\
\hline $\mathbf{1}$ & 1,5 & $1,2,3,6,7$ & 1 \\
\hline $\mathbf{2}$ & $1,2,3,4,5,7$ & 2 & 2 \\
\hline $\mathbf{3}$ & 1,3 & 2,3 & 3 \\
\hline $\mathbf{4}$ & 4 & 2,4 & 4 \\
\hline $\mathbf{5}$ & 5 & $1,2,5,6$ & 5 \\
\hline $\mathbf{6}$ & $1,5,6,7$ & 6 & 6 \\
\hline $\mathbf{7}$ & 1,7 & $2,6,7$ & 7 \\
\hline
\end{tabular}

The second column of the above table is the number of unit elements of the corresponding rows of the access matrix, the third is the number of unit elements of the column columns of this matrix. Equality (4) is fulfilled for the 2nd column - level of 
economic security (LES) and the 6th column regulatory support (RS). According to the method of analysis of hierarchies, these factors can be attributed to the low level of priority of the impact on the learning process of business and entrepreneurship managers. Next, in Table 3 , we remove rows 2 and 6 , and in the ith columns we delete the numbers 2 and 6 . We get Table 4, which is the basis for calculating the second iteration of finding the numbers of the level of influence of factors that determine the next level of the hierarchy.

Table 4. Computational table for building a model of the hierarchy of institutional factors affecting the learning process of business and entrepreneurship managers

\begin{tabular}{|c|c|c|c|}
\hline $\mathrm{I}$ & $\mathbf{S}\left(\mathbf{z}_{\mathbf{i}}\right)$ & $\mathbf{P}\left(\mathbf{z}_{\mathbf{i}}\right)$ & $\boldsymbol{S}\left(\mathbf{z}_{\boldsymbol{j}}\right) \cap \boldsymbol{P}\left(\mathbf{z}_{\boldsymbol{j}}\right)$ \\
\hline $\mathbf{1}$ & 1,5 & $1,3,7$ & 1 \\
\hline $\mathbf{3}$ & 1,3 & 3 & 3 \\
\hline $\mathbf{4}$ & 4 & 4 & 4 \\
\hline $\mathbf{5}$ & 5 & 1,5 & 5 \\
\hline $\mathbf{7}$ & 1,7 & 7 & 7 \\
\hline
\end{tabular}

In the second iteration, equality (4) is fulfilled for the 3rd - financial policy (FP), the 4th - international development and innovation in the field of sports (ID) and the 7 th - level of business education in world (LBE). These institutional factors determine the next level of hierarchy. Therefore, we delete rows 3, 4, and 7 from Table 5, and the numbers 3, 4, and 7 are removed in columns 2 and 3. Without further calculations, it can be argued that 1-implementation of quarantine activities (QA) and 5 - education development system in world (WDS) threats factors of influence on the learning process of business and entrepreneurship managers.

Having located these institutional factors at certain levels, we obtain a hierarchically structured model (Figure 2) that simulates the priority of their influence on the learning process of business and entrepreneurship managers.

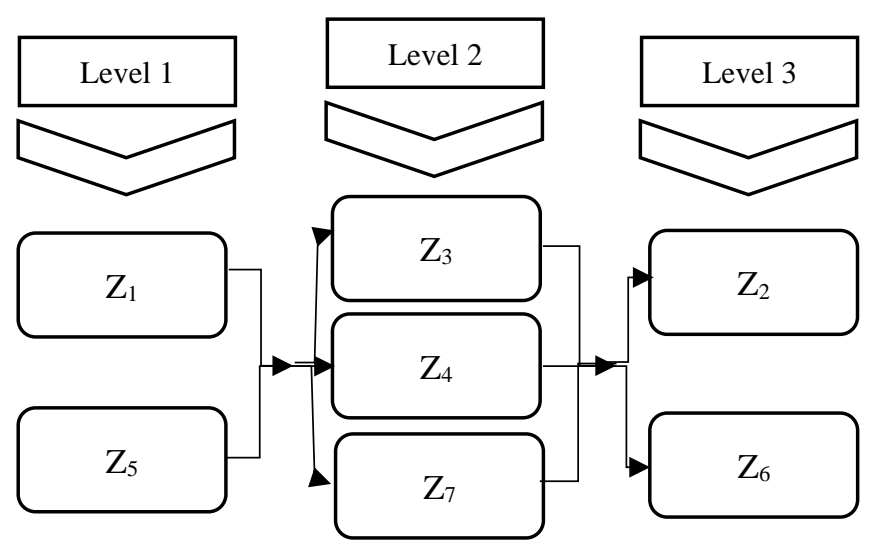

Figure 2. A model of the hierarchy of institutional factors affecting the learning process of business and entrepreneurship managers 
Applying the theory of graphs, we were able to hierarchically streamline and structure the identified using an expert survey of institutional factors affecting the learning process of business and entrepreneurship managers and establish the priority of the impact of each of them on the learning process of business and entrepreneurship managers.

\section{Conclusions}

During the study, the experience of the introduction of the educational process in educational institutions of the United States of America was analyzed.

The next step in our study was to analyze the degree of influence of institutional factors on the learning process of business and entrepreneurship managers. For this, from higher education institution, the analysis of which is presented in the theoretical part of the study, we selected experts belonging to all cohorts of participants in the educational process. They identified seven main institutional factors affecting the learning process of business and entrepreneurship managers. Using the basics of graph theory and the hierarchical structuring methodology, we identified two of the most influential factors in the learning process for business and entrepreneurship managers: implementation of quarantine activities and education development system in world.

Thus, the scientific contribution of the authors consists in a comprehensive analysis of the US experience in introducing innovations into the education system of business and entrepreneurship managers. In addition, we used graph theory, which is rarely used in such subjective studies, has brought greater clarity and specificity to the field of improving the process of training business and entrepreneurship managers.

In the future, we plan to expand the boundaries of our research in the context of an increase in the number of subjects, countries and respondents, and also taking into account other factors influencing the learning process of business and entrepreneurship managers.

\section{References}

Allen, S. (2015). "The Hyper-Connected Workforce." Harvard Business Review. URL: https://hbr.org/resources/pdfs/comm/verizon/HBR_Report_Verizon_Workforce.pdf

Alter, S. (2013). "Work System Theory: Overview of Core Concepts, Extensions, and Challenges for the Future." Journal of the Association for Information Systems 14 (2), 72-121

Bandara, W., Chand, D.R., Chircu, A.M., Hintringer, S., Karagiannis, D., Recker, J.C., van Rensburg, A., Usoff, C., Welke, R.J. (2010). Business process management education in academia: Status, challenges, and recommendations. Communications of the Association for Information Systems, 27, 743-776.

Bergener, K., vom Brocke, J., Hofmann, S., Stein, A. and vom Brocke, C. (2012). On the importance of agile communication skills in BPM education: Design principles for international seminars. Knowledge Management \& ELearning: An International Journal, 4(4), 415-434.

Borsnik, U., Kutnar, K., Marusic, D., Janezic, D. (2008) Interconnection networks for parallel molecular dynamics based on hamiltonian cubic symmetric topology. J Math Chem, DOI: https://doi.org/10.1007/s10910-0089412-5

Chevaillier, T. (2002). Higher education and its clients: Institutional responses to changes in demand and in environment. Higher Education Journal, Volume 44, Issue 3-4, 303-308.

Drucker, P. (2000). Management Practice / M: Publishing House. house "Williams".

Duque, L.C.; Weeks, J., R. (2010), Towards a Model and Methodology for assesing Student Learning Outcomes and Satisfaction, Quality Assurance in Education Journal, Vol.18, No.2, p. 4 -105.

Evans, P, Pucik, V and Barsoux, J-L (2002) The Global Challenge. Frameworks for International Human Resource Management. Chicago: McGraw-Hill/Irwin.

Grugulis, I and Styanova, D (2020) Skills and Performance, SKOPE Issue Paper 9, Economic \& Social Research Council, UK. 
Harmon, P. and C. Wolf (2014). The State of Business Process Management. URL: http://www.bptrends.com/bpt/wp-content/uploads/BPTrends-State-of-BPM-Survey-Report.pdf

Hogben, L. (2004) Spectral graph theory and the inverse eigenvalue of a graph. Presentation at Directions in Combinatorial Matrix Theory Workshop, Banff International Research Station.

Petrenko V. O. (2020) Training Future Managers Intercultural Professional Interaction Competence in Higher Education Establishment. World Scientific News. Poland: WSN. Vol. 54. P. 165-179.

Sylkin, O., Kryshtanovych, M., Zachepa, A., Bilous, S., \& Krasko, A. (2019). Modeling the process of applying anti-crisis management in the system of ensuring financial security of the enterprise. Business: Theory and Practice, 20, 446-455. https://doi.org/10.3846/btp.2019.41

Wilson, R. (2013). "Skills anticipation-The future of work and education." International Journal of Educational Research 61 (2013), 101-110.pringer, Cham 